\title{
Aluminium High Pressure Die Casting Application on Rear Frame Rails
}

\author{
Ibrahim Ozbay ${ }^{1 *}$, Tamer Aydiner', Gürkan Yilmazoglu' ${ }^{1}$, Hafize Celik', Levent Aksel', Harun Yeni', \\ Metehan Bayramoglu', Erdem Aydogmus ${ }^{2}$
}

TOFAŞ Türk Otomobil Fabrikası A.Ş, R\&D-Underbody, Bursa-TURKEY

${ }_{2}^{2}$ CELIKEL Aluminyum Döküm Imalat San.ve Tic.A.Ş. Kocaeli-TURKEY

I. Ozbay (0000-0001-9910-9011), T. Aydiner (0000-0002-6401-5100), G. Yilmazoglu (0000-0002-1811-7827), H. Celik (0000-0001-7572-073X), L. Aksel (0000-0003-2944-5030), H. Yeni (0000-0002-8200-443X), M. Bayramoglu (0000-0003-4683-8522), E. Aydogmus (0000-0001-6444-1989)

\begin{abstract}
Due to the highly competitive environment in automotive industry and environmental restrictions, car manufacturers tend to use higher mechanical properties but better performance in lightweighting instead of traditional structural materials such as steel. Aluminium alloys are a good example of this application since they are 3 times lighter than steel. Aluminium is proposed to use in car body structure design because of its high performance of durability, and in addition with proper geometry and heat treatment the mechanical properties will be also valid for structural parts. Using casting as a process enables to make topology optimization and having more complex shapes that has better strength but less weight with respect to sheet metal stamping.

Rear rail reinforcement support bracket is one of the most suitable component of body in white, where topologically optimized aluminium die casted part could be applied. In a conventional reinforcement support bracket, more than one steel stamped parts are used to have desired performance of stiffness and durability which results in much more complex structures in terms of design, formability and assembly.

In this study, a new part designed and produced by high pressure casting method to obtain the same performance of current solution. Additionally to obtain better mechanical properties different heat treatments have been tested and the optimum heat treatment cycle has been determined. The new design has been compared to current one with virtual validation tools and the results have been given as comparison.
\end{abstract}

Keywords: Rear Rail Reinforcement Support Bracket, Al Alloy, High Pressure Die Casting, Body In White (BIW).

\section{INTRODUCTION}

Due to increased safety standards in the automotive industry, the body structure of new generation vehicles need to have better structural integrity and energy absorption capacity during crash. At the same time, the carbon emission should also be lower because of the new environmental rules. Engine and gearbox efficiency, vehicle weight, aerodynamics and rolling resistance are key factors affecting carbon emissions and fuel consumption.100 kg weight saving of a car may result in 9 grams of $\mathrm{CO}_{2}$ saving per $\mathrm{km}$. Therefore a reduction of vehicle weight is mandatory, as the most effective measures to reduce $\mathrm{CO}_{2}$ emission and at the same time maintain performance, driving quality and -most of all- sa- fety. [1] As the automotive structure possesses about 40\% weight of full vehicle, the weight reduction in body structure is one key way to achieve fuel efficiency, harmful emissions reduction and raw material saving [2].

There are several design methodologies, innovative material options such as aluminium, magnesium, composites etc. and choosing correct materials are the most important effe$\mathrm{ct}$ for reducing vehicle body weight. Aluminium comes head of materials that will use to reduce body because of cost, workability, corrosion resistance and recycling advantages and widespread use in automotive industry. [3]

Aluminium alloys have the following advantages over steels for automotive applications:
${ }^{*}$ Corresponding authour

Email: Ibrahim.Ozbay@tofas.com.tr
European Mechanical Science, June 2019; 3(2): 62-67 doi: https://doi.org/10.26701/ems.422299

Received: May 10, 2018

Accepted: April 21, 2019 
- Lower density $\left(2,7 \mathrm{~g} / \mathrm{cm}^{3}\right.$ of density compared to steels with $\left.7,87 \mathrm{gr} / \mathrm{cm}^{3}\right)$

- Higher impact energy absorption per unit weight

- Higher thermal conductivity, which is useful for radiator cores and other heat exchanger applications [4]

In this paper for lightweight body structure, a new suspension support bracket on the rear rail is redesigned as single part. The new designed bracket is produced by using aluminium alloy instead of steel materials and by high pressure casting process. Today, high-pressure aluminium alloy casting chassis parts are not used by Turkish automobile manufacturers, although they are used by many high-end market automobile manufacturers. As a result of this study, around $3,0 \mathrm{~kg}$ per vehicle weight reduction has been achieved, while eliminating a large number of spot welding joint. The new designed bracket verified with all aspect of performance requirements of the vehicle like crashworthiness, durability and NVH (Noise, vibration, and harshness).

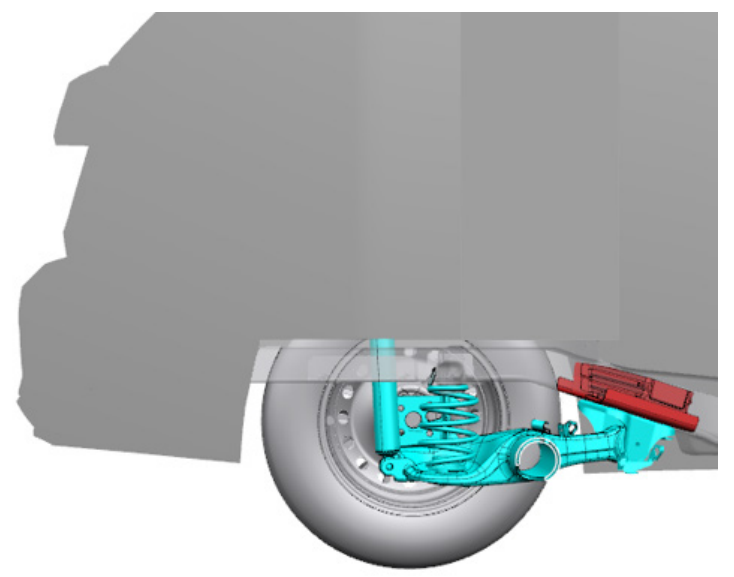

Fig.1 Connection of Rear Suspension to Body experımental procedure

Rear suspension support brackets (red colour in
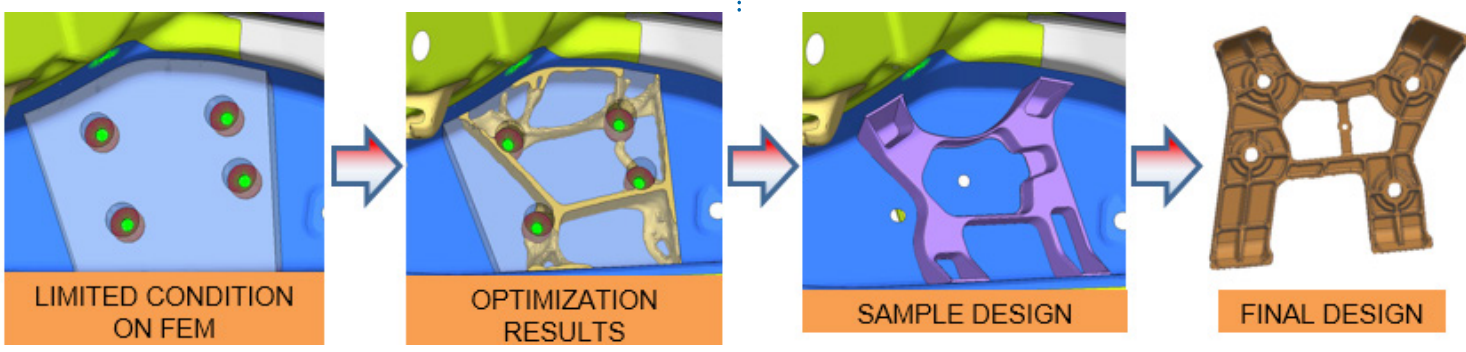

FIG.3 The Topology Optimization and Final Design

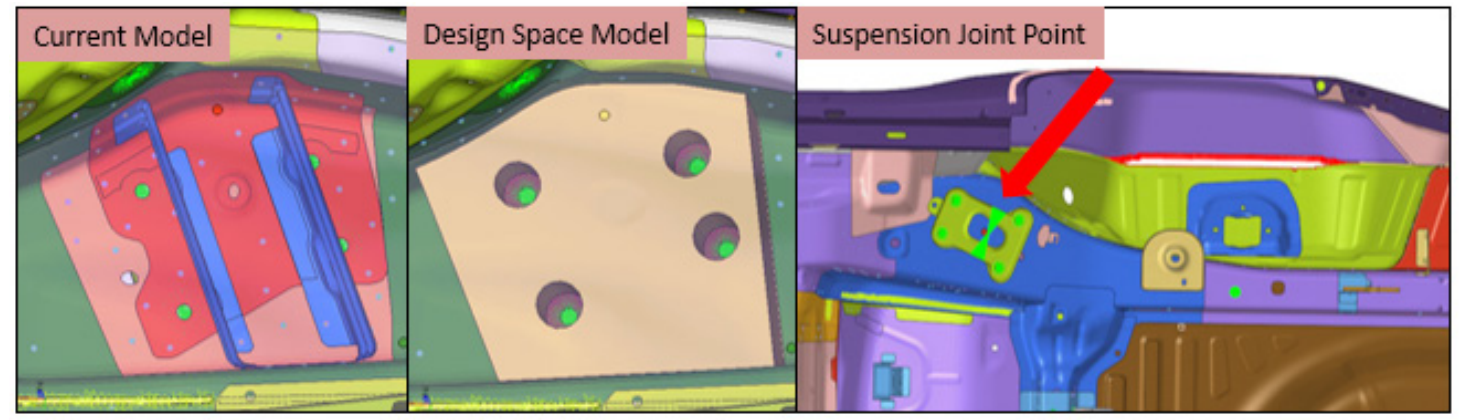

FIG.4 Current model, design space model in U-section body arm and Suspension Joint Point. 


\begin{tabular}{|c|c|c|c|c|c|c|c|c|c|c|}
\hline$[8 \%]$ & Si & $\mathrm{Fe}_{\mathrm{g}}$ & $\mathrm{Cu}$ & Mn & $\mathrm{Mg}$ & $\mathrm{Zn}$ & ก & Sr & P & others \\
\hline min. & 9.5 & & & 0.5 & 0.1 & & 0.04 & 0.010 & & \\
\hline $\max$. & 11.5 & 0.15 & 0.03 & 0.8 & 0.5 & 0.07 & 0.15 & 0.025 & 0.001 & 0.10 \\
\hline
\end{tabular}

Chart 1. Chemical composition of Silafont-36 [6]

ing parts into the results of the topology optimization analysis. The final design has been made by taking into account the requirements of the high pressure die casting method and the dimensional differences that may occur during production and assembly (Fig.3).

For topology optimization on FEM (Finite Element Method), the design space has been created to be used in optimization problem by determining the available volume in the U cross-sectional crossmember (Fig.4). Unit loads have been applied on $\mathrm{X}, \mathrm{Y}$ and $\mathrm{Z}$ directions on the suspension joint point. Under unit loads, topology optimization analysis has been performed to provide maximum stiffness and obtain the minimum weight. [5]

Nuts have been placed in the casting design to connect the suspension system to the body. Structural adhesive is also used for connection of aluminium bracket to steel sheet body (Fig.5).
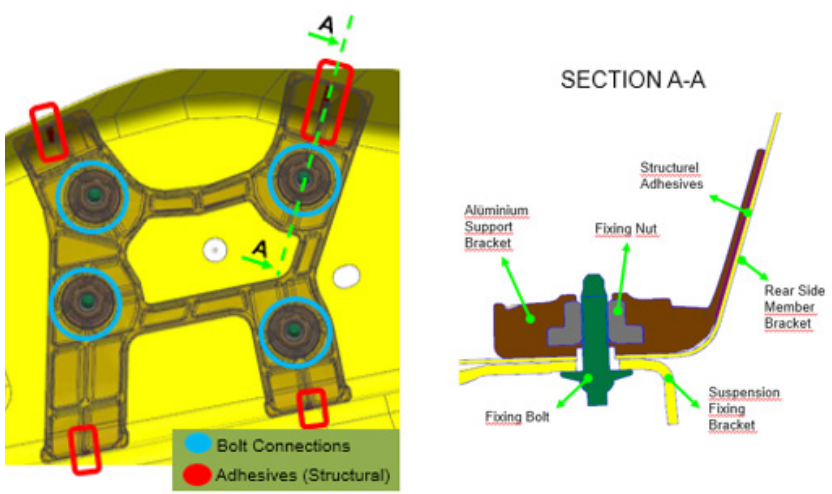

FIG.5 Fixing Method and Section View

\subsection{Material Selection and Determination of Heat Treatment}

Due to the fact that the bracket is an important part of the connection of the suspension system, the mechanical strength of the aluminium alloy used in casting, its stability and material properties are expected to be suitable for serial production conditions. Furthermore, since the forces from the suspension system create a torsional effect on the bracket, the material to be used must have a high elongation value. In addition, heat treatment can be applied to the bracket to obtain the desired mechanical values and elongation.

Silafont-36 (AlSi10MnMg) is an injection casting alloy obtained by using $99.8 \%$ pure aluminium. Narrow tolerance ranges in elements, unchanging and provides a good casting quality [6].

Casting applications also have the following features:

- Very good pouring,

- High fatigue strength
- Suitable for rivets and similar connection applications,

- Very good elongation values in casting,

- Maximum elongation values after heat treatment

Due to the iron level is limited in the composition, unique elongation and bending results can be observed which tends to absorb energy of crash. Iron tends to create intermetallic particles in microstructure which lets crack formation during impacts. Mg level designates heat treatment fine adjustment. With respect to \% Mg level increase (\%0,35 $\% 0,50)$ tensile and yield strengths slightly increases with a little bit elongation loss.

Besides alloy composition and heat treatment operation; HDPC process should be adequately optimised. For instance; after melting operation flux usage is forbidden due to the fact that every single external addition inside to the melt; can act as contaminant on the entire component. So flux usage should not be in process flow. This means; AlSi10MnMg alloy should be melted in dedicated furnace and should be maintained in dedicated holding furnaces for elimination of contaminants coming from alloy mixture.

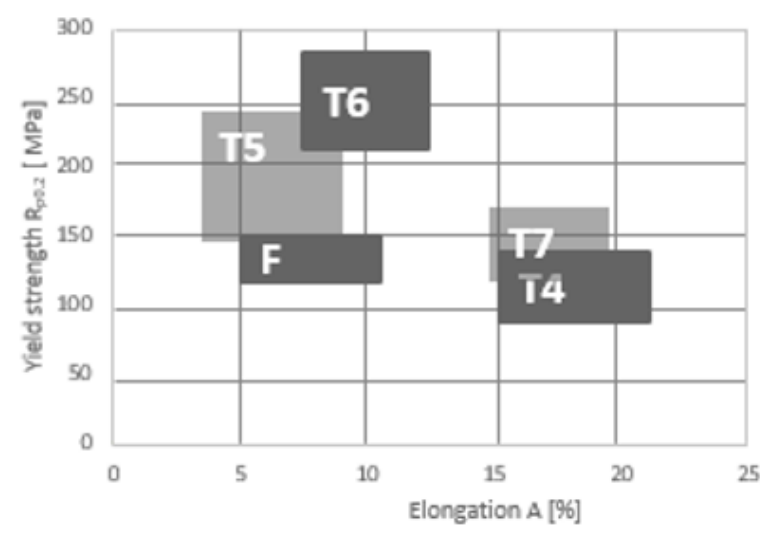

F: As-cast state

Heat treatment without solutionizing:

T5: Quenched directly after removal from the die and artificially aged

Heat treatment with solutionizing:

T4: Solutionized, quenched and naturally aged for more than 6 days

T6: Solutionized, quenched and artificially aged

T7: Solutionized, quenched and overaged

FIG.6 Silafont-36 Yield strength and elongation in various heat treatment states [6]

The most common heat-treatment temper for these alloys is T6, which is comprised of solution heat treatment and quenching, followed by artificial aging. [7] In the solution step, the material is heated to a temperature below the melting start temperature, then cooled rapidly at this temperature to produce an over saturated solid solution. The aim here is to dissolve the elements that will create precipitation harde- 
ning and to be trapped in solid solution. The quenching process ensures that the dissolved elements remain in solution. Artificial aging process is to accelerate aging by keeping the parts in the temperature range of $100-200^{\circ} \mathrm{C}$ for $1-25$ hours.

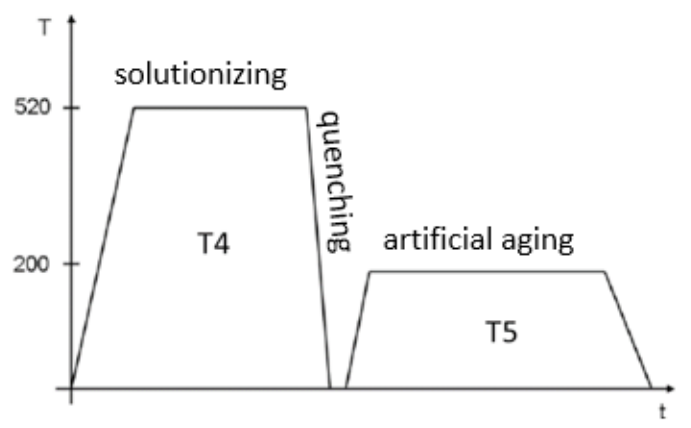

FIG.7 T6 heat treatment schematic representation (temperatures and durations may vary depending on the type of material, design and requirements)

In order to obtain sufficient and appropriate mechanical properties, different heat treatments were applied to the $\mathrm{Si}$ lafont-36 samples and tensile tests were performed. Solution temperature for $\mathrm{T} 4$ heat treatment is $520^{\circ} \mathrm{C}$ and stand-by time is 45 minutes, under 150 seconds to room temperature. $\mathrm{T} 5$ artificial aging temperature was determined to be $180^{\circ} \mathrm{C}$ and standby time was 120 minutes (Fig.7).

\begin{tabular}{|c|c|c|c|c|}
\hline & $\begin{array}{c}\text { Heat Treat- } \\
\text { ment }\end{array}$ & $\begin{array}{c}\text { Yield Strength_ } \\
\text { MPa }\end{array}$ & $\begin{array}{c}\text { Tensile Strength_ } \\
\text { Mpa }\end{array}$ & Elongation_\% \\
\hline 1 & Raw & 139 & 296 & 8,8 \\
\hline 2 & T4 & 100 & 220 & 20,6 \\
\hline 3 & T5 & 191 & 313 & 5,3 \\
\hline 4 & T6 & 220 & 300 & 9 \\
\hline
\end{tabular}

Chart 2. Experimental study parameters and results

According to results given by this study, T6 heat treatment has been applied while silafont-36 has been chosen as raw material.

\section{RESULT AND DISCUSSION}

\subsection{Casting Analysis}

Various casting analysis has been made for possible problems that could be experienced during casting of design. The bracket design has been optimized according to these analysis and evaluation results. According to the results of the fill analysis, the potential porosity risks have been eliminated by improving the flow of liquid metal and trying to homogenize the thickness. According to the results of liquid metal solidification analysis, additional cooling lines and multiple gates have been defined in the mold to provide a stable solidification and to avoid possible distortion problems. [8] (Fig.8).
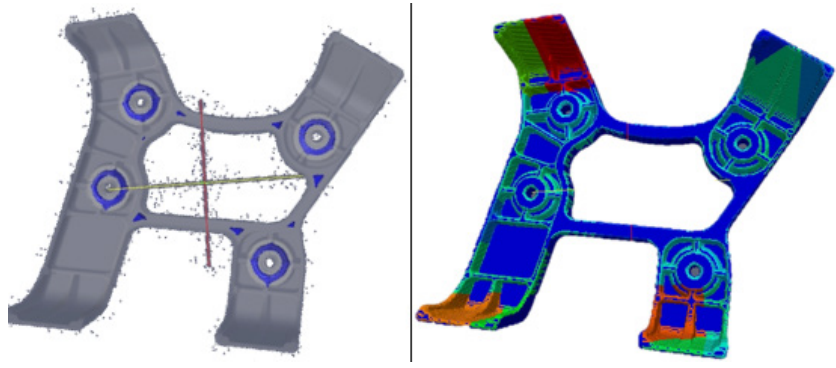

FIG.8 Porosity and Distortion Analysis and of Design

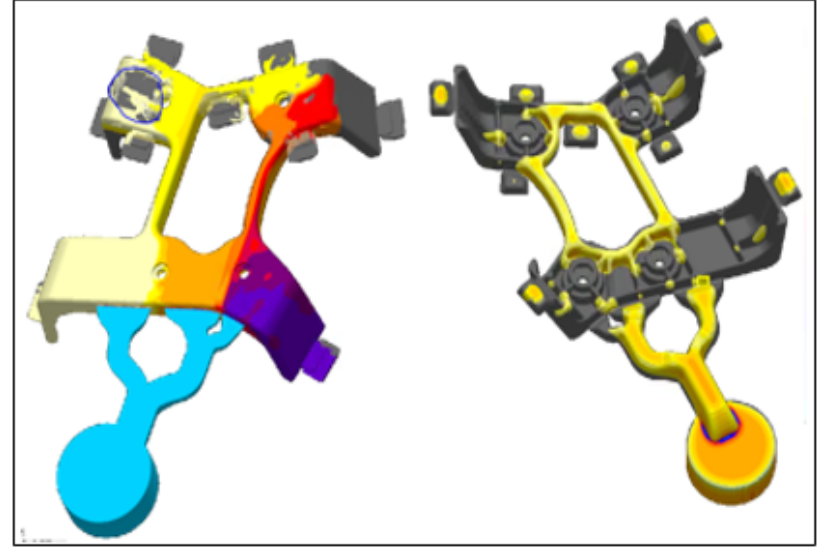

FIG.9 Mold Filling and Solidification Analysis and of Design

\subsection{Virtual Verification}

For the safety performance of the vehicle, the structure of the suspension system and the mechanical properties of its components are very important. The suspension system and its components must have enough stiffness to meet repetitive and sudden shock loads from the road. Also, as the suspension system is subjected to dynamic load, its components must have high fatigue strength. Recently, various structural and mechanism analysis techniques have been applied to vehicle development contributing to simplification of prototyping and reduction of labour time required for vehicle development [9]

Rear Crash Performance (TRIAS 33): For the evaluation of the rear crash performance of the vehicle TRIAS 33 has been executed. TRIAS 33 basically controls the deformations on the fuel pipes and fuel tank. Within the TRIAS 33, a rigid barrier has been impacted with $52 \mathrm{~km} / \mathrm{h}$ to the vehicle from the rear side. [10] (Fig.10).

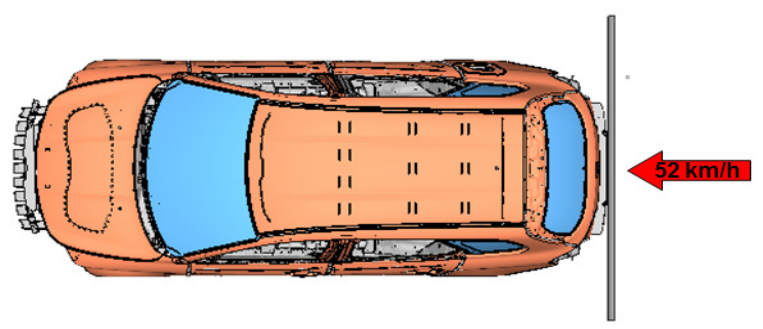

Fig.10 Rear Impact Condition of the Vehicle for TRIAS 33 Validation

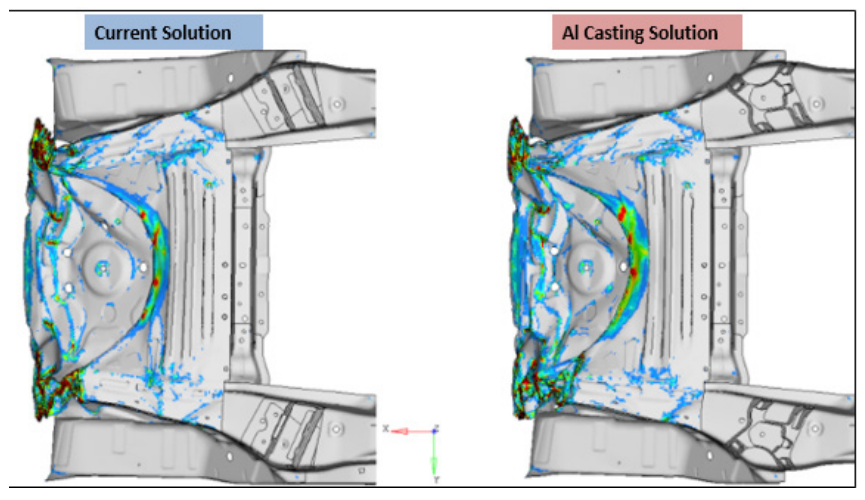

FIG.11 Rear impact virtual analysis result - bottom view

This analysis for the $\mathrm{Al}$ casting bracket did not show any negative results. 
Fatigue Performance: New designed aluminium alloy bracket on vehicle has been verified also with respect to fatigue life of the vehicle. Due to repeated and sudden shock loads coming into the suspension system, the fatigue strength of the design must be high. In the design phase of the bracket, design changes have been made in the areas under the target value observed in the fatigue analysis, and the bracket fatigue performance has been improved. Fatigue life performance has been improved by increasing the cross-sectional thickness and / or by softening the sharp transition of form for the points in question (Fig.12).
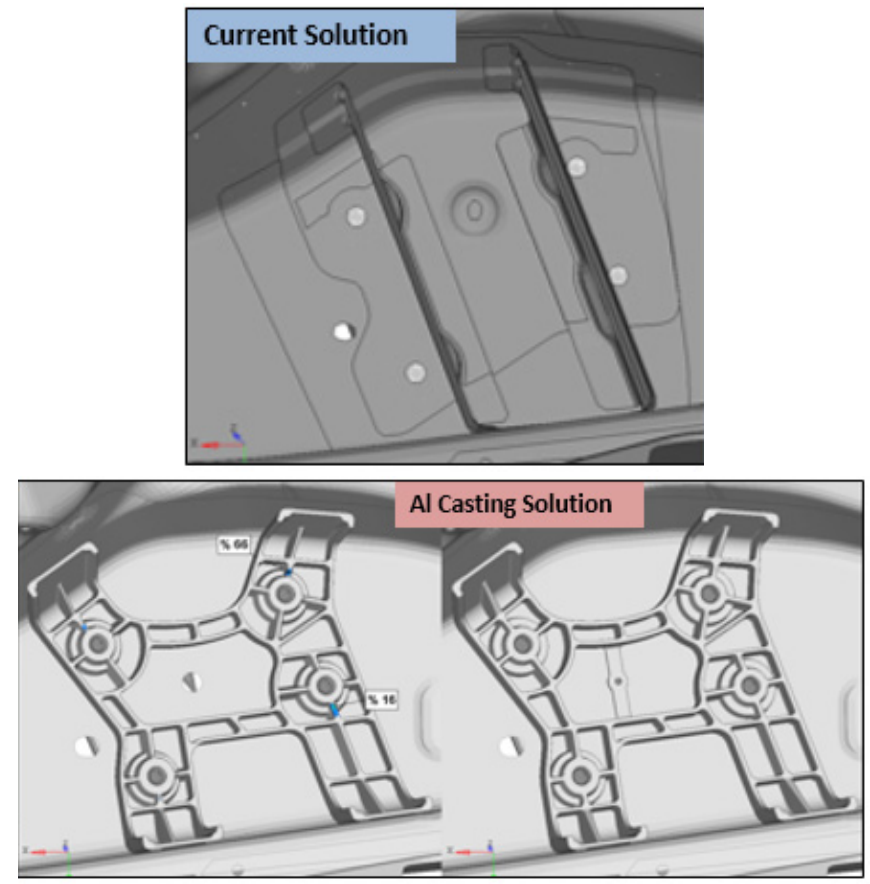

Fig.12 Fatigue Life Analysis

Modal Analysis Performance: Modal analysis for NVH calculations is the basic analysis that determines the vehicle body performance in the product development process. For the project development process, all changes made on the vehicle components are continuously checked as well as the effect on the body NVH performance. Modal analysis is performed to calculate the natural frequencies of the vehicle. BIW model is used when modal analysis is performed. (Fig 13) With the use of aluminium alloy suspension support bracket instead of standard sheet metal parts, the vehicle torsional mode increased $\sim 0.5$ hertz.

For the current solution and the Al casting solution, the dynamic stiffness analysis of the related region have been made and the dynamic stiffness values have been increased according to the current situation.

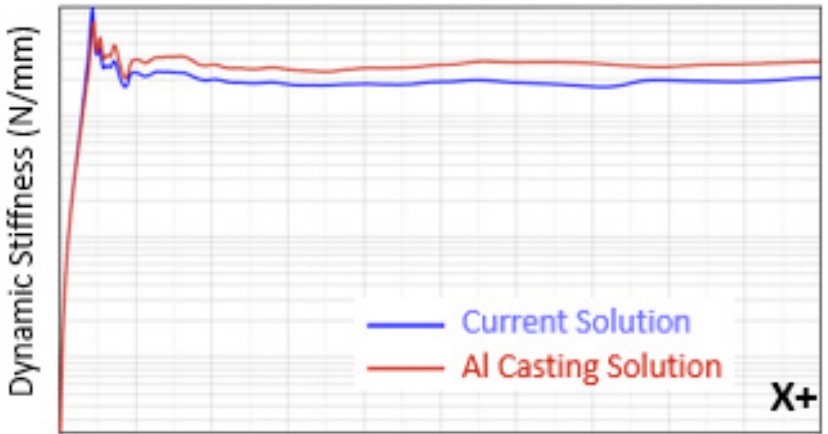

\section{Frequency $(\mathrm{Hz})$}

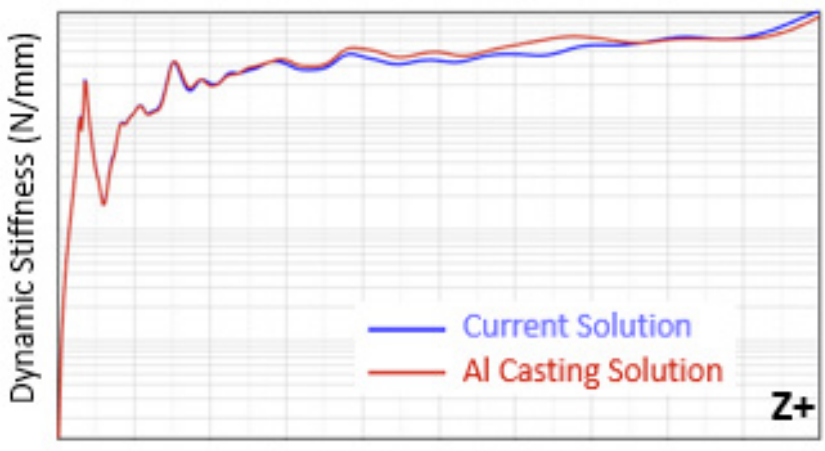

Frequency $(\mathrm{Hz})$

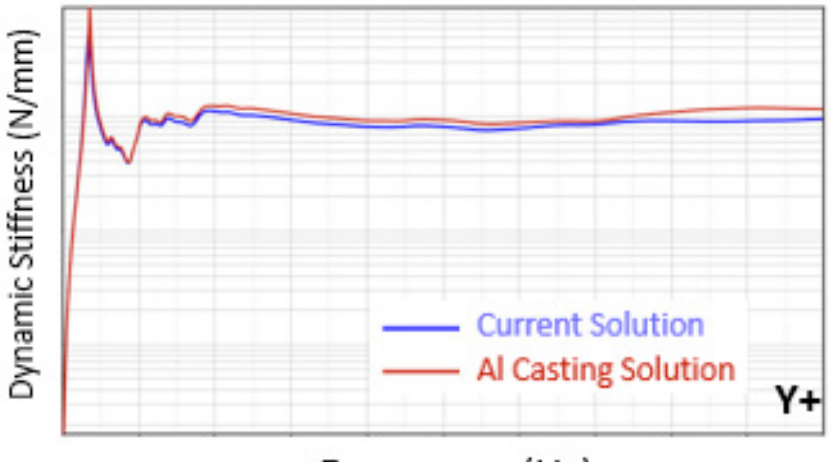

Frequency $(\mathrm{Hz})$

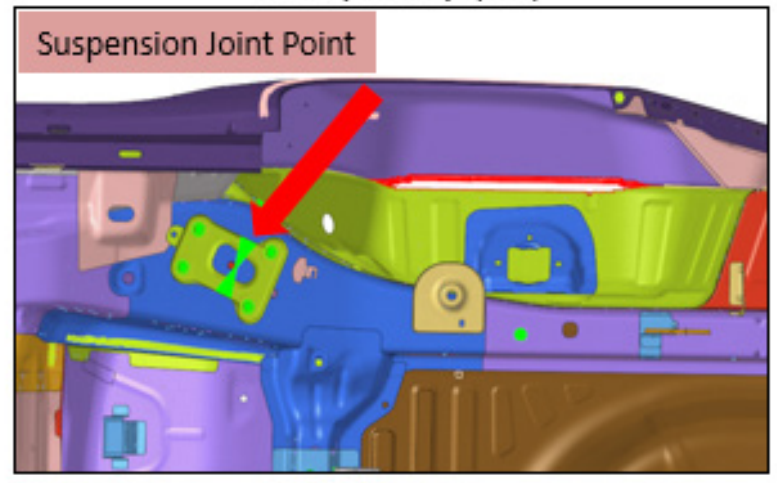

Fig. $13 \mathrm{NVH}$ analysis for suspension joint point

Torsional-Bending Stiffness Performance; With the use of aluminium alloy suspension support bracket instead of standard sheet metal parts, the torsional mode of the vehicle has been increased by $3-5 \%$. 


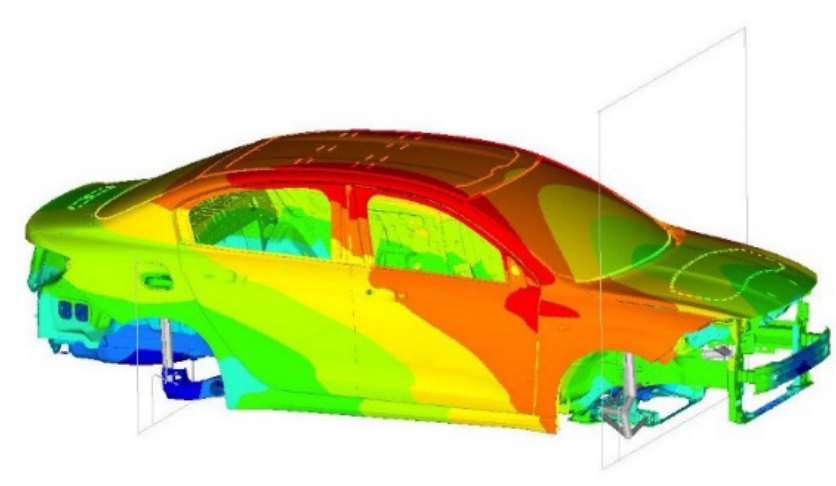

Fig.14 Torsional- Bending Stiffness Analysis in BIW model

\section{CONCLUSION}

Aluminium has been recognized in the automotive industry as an ideal lightweight material within reasonable cost limits and weight saving in mass production without sacrificing performance and safety. In the present study, within the body structure light weighting trials, a new rear suspension support bracket on the rear rail is redesigned to be produced with aluminium alloy material and controlled virtually. The new rear suspension support bracket has achieved all safety and structural requirements on virtual analysis with $3.0 \mathrm{~kg}$ of weight saving and \% 35 spot welding saving on rear rails. By redesigning suspension support bracket from aluminium alloy instead of standard sheet metal parts, amount of $\mathrm{CO}_{2}$ is reduced 0.27 gr per each $\mathrm{km}$.

\section{ACKNOWLEDGEMENTS}

This study is supported by TÜBİTAK (The Scientific and Technical Research Council of Turkey) with 1160451 Project Number. We would like to thank TÜBİTAK for its financial support throughout the project.

\section{REFERENCES}

[1] Hirsch, J. (2011). Aluminium in Innovative Light-Weight Car Design. Materials Transactions, 52(5): 818-824, DOl:10.2320/matertrans.L-MZ201132.

[2] Altınok, E., Kayserili, H., Mert A., Altınel, S.A. (2017). Lightweight Door Ring Solution in Car Body Development. International Journal of Advances on Automotive and Technology, 1(3): 131-136, DOI: 10.15659/ijaat.17.07.529.

[3] Başer, T. A. (2013). Alüminyum alaşımları ve otomotiv endüstrisinde kullanımı. Mühendis ve Makina, 53(635): 51-58.

[4] Mallick, P.K. (2010). Materials, Design and Manufacturing for Lightweight Vehicles, Cambrighe, UK: Woodhead Publishing Limited.

[5] Wu, P., Ma, Q., Luo, Y., Tao, C. (2016). Topology Optimization Design of Automotive Engine Bracket. Energy and Power Engineering, 8(4): 230-235, DOI: 10.4236/epe.2016.84021.

[6] KG, Rheinfelden Alloys GmbH \& Co., "Primary Aluminium Alloys for Pressure Die Casting," A company of the Aluminium Rheinfelden Group, Friedrichstraße 80.

[7] Chaudhury, S.K., Apelian, D. (2006). Fluidized Bed Heat Treatment of Cast Al-Si-Cu-Mg Alloys. Metallurgical and Materials Transactions A, 37A: 2295-2311.

[8] M. Hartlieb, (2013). Aluminium Alloys For Structural Die Casting.
Die Casting Engineer, 41.

[9] Kurisu, F., Miyauchi, K. (2004). Application of ADAMS Mechanism Analysis Software To Powertrains. Mazda Technical Review, 22: 4449.

[10] Aksel, L., Efendioğlu, Ş., Yeni H., Bilge, Ç. (2016). Weight Reduction Study on BIW by Using Boron Alloyed Hot Stamping Solution of Front Frame Rail Instead Conventional HSS or AHSS Applications. in International Conference on Advanced Technology \& Sciences.

[11] Joost, W. J., Krajewski, P.E. (2017). Towards magnesium alloys for high-volume automotive applications. Scripta Materialia, 128: 107112, DOI: 10.1016/j.scriptamat.2016.07.035 